\title{
DYSPLASTIC GROWTH DIFFERENTIALS IN PATIENTS WITH PSYCHIATRIC DISORDERS STUDIES ON THE MORPHOLOGY OF MATURITY
}

BY

\author{
J. W. LOVETT DOUST \\ From the Department of Psychiatry, University of London \\ Institute of Psychiatry, Maudsley Hospital
}

This paper is concerned with some aspects of the morphology of man, as they present in relationship to the occurrence of psychiatric disorder. Kallmann in the U.S.A. and Slater in England, among others, have initiated fundamental work, summarized recently by Slater (1950), dealing with the genetic linkages involved in the causation of mental illness, while the sociological, clinical, psychiatric, and especially psycho-analytic literature provides an overwhelming if diffuse body of evidence pointing to the importance of environmental factors. It is not a function of this paper to review this literature; it is necessary only to mention its existence for orientation purposes since the studies which follow will necessarily have to be interpreted in terms of the relative importance of these two fundamental aetiological influences.

The present investigation resulted from two assumptions based on the clinical observation of mentally ill patients in a psychiatric hospital. These were firstly, that there is something about the physical appearance of such patients which reflects their relative incapacity to remain emotionally stable under stress, and secondly, that, if this clinical impression be true, then over the length of the patient's life the separate features of his physical appearance on which the impression is based must have resulted from dysplastic or imperfect development at some definite phase of his growth, since such features cannot be assumed to appear suddenly out of the blue. Some of the differentials contributing to the clinical "hunch" have been measured and analysed by Draper and his co-workers (1944) at Columbia University with respect to physical illnesses such as cholecystitis, peptic ulceration, rheumatoid arthritis, rheumatic fever, and migraine. Features of significance in Draper's data are convincing, not only because of the comprehensive nature of his morphological observations, but also because of their ontogenetic basis. This point will be referred to later, but it is worth remarking here that, in the field of psychiatry, the scientific strictures of the developmental hypothesis in biology have been largely neglected. Somatotypology has been widely employed by Kretschmer (1936) and other authors to reveal constitutional dysplasias in psychiatric patients but these studies remain largely descriptive, and therefore sterile, in so far as they do not lead to an increase in understanding of causation and later of rational therapy in mental disorders. The studies of Sheldon and others (1941, 1942) suffer from the same purely descriptive faults but do at least add one set of useful data to those of Kretschmer, i.e., an analysis of the predominating germ-layer involved in the resulting dysplasia. Both workers, moreover, have pointed to the concordance of emotional, temperamental, and other psychological features of the personality with the constitutional somatotype of the individual examined, each agreeing that the extreme dysplasias in any orientation of their classifications tend to be associated with overt mental illness of a particular type (Kline and Tenney, 1950).

\section{Experimental Procedure}

The objects of the investigation were to discover if any tendencies towards particular morphological configuration exist between patients suffering from a variety of psychiatric disorders and a healthy control group - such physical features being chosen for investigation which represent either fixations or deviations from the processes of normal growth and development. Many of the anthroposcopic observations and measurements reported here are those employed by Draper and his associates (1944) at the Constitution Clinic of Columbia Medical Centre, New York. They provided rewarding indices of differential dysplasia in their series of physically ill patients, and it seemed desirable to test their applicability to the psychiatrically disturbed patient. Other observations have been taken from the descriptions of Kretschmer (1936) of "infantile", "hypoplastic", and other dysplastic constitutional types. In speaking of infantile 
characteristics, Kretschmer definies them (p. 81) to include those in which the shapes and modelling of the "minor proportions in the total body complex" are "typically childish".

Measurements were undertaken whenever possible, other assessments being made qualitatively on a rating scale basis. The actual items and traits used will be listed here, together with the means used for assessing them and the justification for their inclusion at the ontogenetic level.

\section{A. Anthroposcopic Qualitative Observations}

(1) Characteristics relating to Hair and Pigmentation.-It is a common observation that, after loss of the lanugo, far more babies born in Great Britain acquire hair which is fair in colour, and, at birth, nearly all have blue eyes. Rapidly or slowly, these pigmentations (or lack of them) change, and the distribution of fair hair and blue eyes becomes fairly evenly distributed with dark hair and brown eyes in the adult population. Such in any event is the impression gained from the observation of infants as compared with adults in general. It seemed worth while to include these features separately in our analysis and to observe both what the actual adult incidence of these traits was and also whether it was displaced in a psychiatric population. The rating scale method was used, the subjects being assessed clinically as to the colour of their hair and that of their eyes. A similar impression relates to the incidence of irregular pigmentation of the skin and the presence or absence of freckling of the face and upper arms was noted. Finally the length of the eyelashes was estimated, the long, curving lashes of infancy having been found normally to grow shorter with increasing age (Draper and others, 1944, p. 190).

(2) Facial Modelling.-Combining the observations of Kretschmer (pp. 82-83) with those of Draper (p. 65) of the hypoplastic face, ratings were made on the presence or absence of the following features:

Eyes, deep-set.

Nose, lateral deviation, saddle or "snub"-shaped nasal root, deep-set nasal root, "retroussé"-shaped of uneven contour, the uncommon type of hypoplastic described by Kretschmer (p. 83) as long and "pulled down" with a pointed tip.

Lips, special attention was given to the size and shape; the small, scanty, shallow upper lip "strained in the middle as if the skin was too short" (Kretschmer) was watched for as was the pouting and full, or conversely, thin protruberance of the lip mucosa; the lower lip was also observed regarding the possible absence of the usual concavity between the midpoint of the mandibular ramus and the mucocutaneous margin.
Mandible, either receding or prognathic (Bolk, 1924). Supra-Orbital Ridge, prominent.

Ears, rated for presence of Darwin's tubercle and existence of a separate lobule, the alternative to this being a dysplastic pinna extending directly on to the neck without lobulation.

Skin of Face, assessed for immaturity if it felt baby-soft to the touch on palpation.

(3) Dental Pattern.-Note was taken of the complete eruption of all the third molar ("wisdom") teeth and of a variety of irregularities of the dental pattern such as the presence of retained deciduous teeth, of absent, small, or twisted upper lateral incisors, of large "buck" canines, and of a wide space between the two central incisors of either jaw; the relative incidence of caries was also rated from inspection of the visible dental hygiene and of the number of fillings (Smyth and Young, 1932).

(4) Epicanthic Fold.-Draper has emphasized the universality of this morphological trait among human infants of all races. Although the complete fold is seldom seen in adult white populations, some of its components (inner canthus lower than outer canthus, skin fold around inner canthus, upper lid margin downwards and inwards) tend to persist, and these remnants have been rated for their occurrence.

(5) Size of Feet.- Since a feature of the infantile constitution is stated to be smallness in actual size as well as of one part in relation to other parts of the body, it was thought desirable to check the incidence of this in our groups. A satisfactory method appeared to be to make an indirect estimate of the foot size from a knowledge of the subject's shoe size. These facts were elicited by questioning.

\section{B. Anthropometric Quantitative Observations}

With the aid of a Walther's rule and its paired visors, a series of seven measurements were taken of various features of the subject's face and hands. The former included:

(i) Actual depth of midline of upper lip from nasolabial junction to mucocutaneous margin. This measurement provided an objective check on the reliability of the anthroposcopic observations of this feature.

(ii) Interpupillary distance measured and compared with

(iii) Breadth of face at the meatal level.

From (ii) and (iii) was computed:

(iv) Interpupillary index (I.P.I.- interpupillary space/facial breadth, Draper, p. 193).

Other measurements were:

(v) Length of nose from nasion to tip.

(vi) Width of bridge of nose.

(vii) Depth of nasal root in region of bridge. 
The rationale for these observations lies in the importance of the progressive development and differentiation of the nasal bridge in relation to the position of the eyes, the latter coming together from their early foetal situation at the sides of the head as the bridge of the nose gradually pushes itself forwards. The final feature investigated was:

(viii) Relative laxity of ligaments about metacarpophalangeal joints. Hyperextensibility of the metacarpo-phalangeal joints, which is as universal a characteristic of infancy as the epicanthic fold, sometimes persists into adulthood ("doublejointedness"). More commonly, however, this trait is largely lost in adolescence. The assessment carried out on this feature was a simple one; the metacarpo-phalangeal joints of the thumbs were put into extension; if extension was possible beyond $180^{\circ}$, the subject was rated as having hyperextensibility of his joints. Both hands were examined so that a comparison could be made between them.

\section{Experimental Populations Studied}

These consisted of 648 subjects (491 males, 157 females). Ages ranged from 15-64 years with a representation roughly equivalent in the various groups included. All subjects were British and of United Kingdom stock.

Two principal groups were differentiated; one of healthy "normal" controls and one of patients. The patients comprised mainly cases of various forms of psychiatric disturbance, but also included a small group of twelve otherwise healthy subjects who had sought out-patient treatment for migraine at a neurological hospital* and another group of eighteen high-grade mental defectives. $\dagger$ The migrainous patients included four males and eight females; all the defectives were males.

(1) Healthy Controls.-These were drawn from two sources. Their total number was 261 (246 males and fifteen females). The larger source was a neighbouring Army Depôt $\ddagger$ which supplied 226 soldiers (N.C.O.s and other ranks) who were detailed to attend at the Institute of Psychiatry in batches of eight per week. The ages of the soldiers ranged from 17-44 years; the first 107 were subjected to the complete battery of tests, and the remaining 119 to only a small number of them. The actual numbers used in each separate investigation are detailed in the Tables. To counterbalance these Army controls, a smaller and more varied group of 35 civilians (twenty males and fifteen females) was examined.

\footnotetext{
* Investigated through the courtesy of Dr. Anne Bolton.

+ For the opportunity of investigation of whom we are indebted to Dr. J. K. Collier Laing, Medical Superintendent of Darenth Park Hospital.

$\ddagger$ Through the kindness of Col. L. Bootle-Wilbraham, D.S.O., M.C.
}

The age range of this civilian group was wider, from 15-65 years, and the subjects included physicians, nurses, technical workers, clerks, and housewives. The civilian group as a whole displayed less cultural homogeneity than the Army group, and, partly because of this and partly on account of its numerical disparity, was not employed when the influence of certain factors (e.g., age) was computed.

(2) Psychiatrically Abnormal Group.-This contained 357 patients $(111+112$ males and 134 females) and was also drawn from two main sources.

One sub-group was drawn from the wards and out-patient department of the Maudsley Hospital. It consisted of 245 patients, of whom 111 were males and 134 females. The age range was from 16-63 years and the diagnostic categories represented included:

\section{7 psychoneurosis \\ 35 psychopathic personality \\ 71 affective disorder-depression \\ 95 schizophrenia \\ 17 idiopathic epilepsy.}

Where these diagnostic categories have been split into the different sub-categories of mental disorder, the proportions have been indicated in the Tables, but such sub-grouping was only carried out when the numerical incidence appeared sensibly to justify it.

The second sub-group which was drawn from the Army* comprised only cases of psychoneurosis, of which 112 were examined. These subjects were all "other ranks", who had broken down during their military service and had been referred to Army psychiatrists for diagnosis and possible invaliding out. The first 56 of these cases were extensively investigated, and the remainder took only a small selection of tests. Mean ages and standard deviations for the different groups have not been computed, but the relative loadings for the various age ranges and diagnostic categories may be assessed from Table VIII, in which the influence of chronological age is derived. Broadly, the mean ages of the two principal subdivisions of the healthy and abnormal groups showed sensible correspondence, though no effort was made to "match" the groups with regard to the age and sex variables.

The Tables show discrepancies in the numbers of subjects examined, especially with regard to the quantitative assessments. One reason for this has already been stated; another was that circumstances made it impossible to administer the complete battery of tests to all individuals. The tabulated

* The patients (all males) were made available for testing through the courtesy of Lt. Col. H. Pozner, R.A.M.C. 
results only refer to such clinical material as it was possible to investigate in sufficient numbers to allow of statistical evaluation. Examinations carried out in small numbers of subjects, and assessments whose actual and "expected" incidence was too low for tests of significance, are referred to briefly in the next section.

\section{RESULTS}

Those results which are of statistical significance may be seen in detail in Tables I to VIII. Eleven rating-scale assessments ( $\chi^{2}$ method) and two sets of measurements (analyses of variance) on morphological characteristics empirically assumed to represent ontogenetic dysplasia proved either to be statistically insignificant or to show too low an expected frequency for evaluation. The traits falling into these categories were the following:

Size of feet (by shoe size)

Presence of receding jaw

Prognathos

Prominence of supra-orbital ridge
Long pulled-down nose with pointed tip

Darwin's tubercle of the pinna

Freckling of face and arms

Excessive dental caries

Difference in hyperextensibility beyond $180^{\circ}$ of metacarpo-phalangeal joints between right and left thumbs

Absence of concavity of lower lip

Length of nose

Breadth of nasal bridge.

Table I lists the positive qualitative data obtained by clinical observation of the subjects. The modified $\chi^{2}$ technique used to establish statistical significance of these measures enabled the separate contributions made by each diagnostic group to be compared with the total $\chi^{2}$ for the trait in question. From a study of each separate "contribution" to the total it was possible to demonstrate which diagnostic group, if any, was principally responsible for the differences between them. For three of the ratings in Table $I, P$ is obviously too great for significance; the figures have been included, however, to indicate

TABLE I

DIFFERENTIAL INCIDENCE AMONG CONTROLS AND TWO PSYCHIATRIC GROUPS (NEUROTIC AND PSYCHOTIC) OF SEVENTEEN QUALITATIVE FEATURES OF MORPHOLOGICAL ONTOGENETIC DYSPLASIA

\begin{tabular}{|c|c|c|c|c|c|c|c|c|c|c|c|c|}
\hline \multirow{2}{*}{\multicolumn{3}{|c|}{$\begin{array}{l}\text { Feature of morphological } \\
\text { dysplasia investigated }\end{array}$}} & \multicolumn{2}{|c|}{ Controls } & \multicolumn{2}{|c|}{ Neurotics } & \multicolumn{2}{|c|}{ Schizophrenics } & \multicolumn{2}{|c|}{$\begin{array}{l}\text { Statistical } \\
\text { significance }\end{array}$} & \multirow{2}{*}{$\begin{array}{l}\text { Principal } \\
\text { contributor } \\
\text { to difference }\end{array}$} & \multirow{2}{*}{$\begin{array}{l}\text { Extent of } \\
\text { contribution } \\
\text { to } \chi^{2}\end{array}$} \\
\hline & & & No. & Incidence & No. & Incidence & No. & Incidence & $\chi^{2}$ & $P$ & & \\
\hline $\begin{array}{l}\text { EYE COLOUR: } \\
\text { Brown }\end{array}$ & $\cdots$ & $\cdots$ & 107 & $46 \cdot 7$ & 56 & $33 \cdot 9$ & 46 & $26 \cdot 1$ & $7 \cdot 020$ & $\cdot 05$ & Controls & $3 \cdot 235$ \\
\hline $\begin{array}{l}\text { HAIR COLOUR: } \\
\text { Dark brown } \\
\text { Fair . . . . }\end{array}$ & $\begin{array}{l}\cdots \\
\cdots\end{array}$ & $\begin{array}{l}\cdots \\
\cdots\end{array}$ & $\begin{array}{l}107 \\
107\end{array}$ & $\begin{array}{l}64 \cdot 7 \\
30 \cdot 8\end{array}$ & $\begin{array}{l}56 \\
56\end{array}$ & $\begin{array}{l}44 \cdot 6 \\
50 \cdot 0\end{array}$ & $\begin{array}{l}46 \\
46\end{array}$ & $\begin{array}{l}45 \cdot 6 \\
34 \cdot 8\end{array}$ & $\begin{array}{l}6 \cdot 395 \\
7 \cdot 315\end{array}$ & $\begin{array}{l}\cdot 05 \\
\cdot 05\end{array}$ & $\begin{array}{l}\text { Controls } \\
\text { Neurosis }\end{array}$ & $\begin{array}{l}3 \cdot 871 \\
4 \cdot 849\end{array}$ \\
\hline \multicolumn{3}{|c|}{$\begin{array}{l}\text { UPPER EYE-LID: } \\
\text { Remnants of epicanthic fold } \\
\text { EYE LASHES: }\end{array}$} & 107 & $47 \cdot 7$ & 56 & $44 \cdot 6$ & 46 & $65 \cdot 2$ & $5 \cdot 096$ & $\cdot 1$ & 一 & 一 \\
\hline $\begin{array}{l}\text { EYE LASHES: } \\
\text { LOng, Curved } \\
\text { EYES: }\end{array}$ & . & $\ldots$ & 107 & $29 \cdot 9$ & 56 & $42 \cdot 9$ & 46 & $58 \cdot 7$ & $11 \cdot 453$ & $\cdot 01$ & Schizophrenia & $6 \cdot 923$ \\
\hline Deepset in face & $\cdots$ & $\cdots$ & 107 & $15 \cdot 9$ & 56 & $35 \cdot 7$ & 46 & $28 \cdot 3$ & $8 \cdot 437$ & $\cdot 02$ & Neurosis & $4 \cdot 277$ \\
\hline \multicolumn{3}{|c|}{ NOSE: } & 107 & $22 \cdot 4$ & 56 & $39 \cdot 2$ & 46 & $39 \cdot 1$ & $6 \cdot 927$ & $\cdot 05$ & $\begin{array}{l}\text { Both } \\
\text { Abnormals }\end{array}$ & $3 \cdot 547$ \\
\hline $\begin{array}{l}\text { Saddle shape } \\
\text { Uneven contour } \\
\text { Root deepset }\end{array}$ & $\begin{array}{l}\cdots \\
\cdots \\
\cdots\end{array}$ & $\begin{array}{l}\cdots \\
\cdots \\
\cdots\end{array}$ & $\begin{array}{l}107 \\
107 \\
107\end{array}$ & $\begin{array}{l}10 \cdot 3 \\
31 \cdot 8 \\
11 \cdot 2\end{array}$ & $\begin{array}{l}56 \\
56 \\
56\end{array}$ & $\begin{array}{l}16 \cdot 1 \\
46 \cdot 4 \\
28 \cdot 6\end{array}$ & $\begin{array}{l}46 \\
46 \\
46\end{array}$ & $\begin{array}{l}28 \cdot 6 \\
52 \cdot 2 \\
47 \cdot 8\end{array}$ & $\begin{array}{r}7 \cdot 858 \\
8 \cdot 308 \\
24 \cdot 600\end{array}$ & $\begin{array}{l}.02 \\
.02 \\
.001\end{array}$ & $\begin{array}{l}\text { Schizophrenia } \\
\text { Schizophrenia } \\
\text { Schizophrenia }\end{array}$ & $\begin{array}{r}5 \cdot 381 \\
3 \cdot 230 \\
14 \cdot 500\end{array}$ \\
\hline \multicolumn{3}{|c|}{$\begin{array}{l}\text { TEETH: } \\
\text { 3rd molars still unerupted... } \\
\text { Irregular dental pattern } \ldots \\
\end{array}$} & $\begin{array}{l}226 \\
107\end{array}$ & $\begin{array}{l}27 \cdot 0 \\
38 \cdot 3\end{array}$ & $\begin{array}{r}112 \\
56\end{array}$ & $\begin{array}{l}33 \cdot 9 \\
51 \cdot 8\end{array}$ & $\overline{46}$ & $5 \overline{2 \cdot 2}$ & $\begin{array}{l}6 \cdot 070 \\
3 \cdot 192\end{array}$ & $\begin{array}{l}\cdot 02 \\
\cdot 3\end{array}$ & Neurosis & $5 \cdot 493$ \\
\hline $\begin{array}{l}\text { UPPER LIP: } \\
\text { Scanty } \\
\text { Pouting } \\
\text { Straight and thin }\end{array}$ & $\begin{array}{l}\cdots \\
\cdots \\
\cdots\end{array}$ & $\begin{array}{l}\cdots \\
\cdots\end{array}$ & $\begin{array}{l}107 \\
107 \\
107\end{array}$ & $\begin{array}{r}18 \cdot 7 \\
44 \cdot 8 \\
6 \cdot 5\end{array}$ & $\begin{array}{l}56 \\
56 \\
56\end{array}$ & $\begin{array}{l}41 \cdot 1 \\
64 \cdot 3 \\
12 \cdot 5\end{array}$ & $\begin{array}{l}46 \\
46 \\
46\end{array}$ & $\begin{array}{l}60 \cdot 8 \\
58 \cdot 7 \\
19 \cdot 6\end{array}$ & $\begin{array}{r}27 \cdot 232 \\
6 \cdot 308 \\
6 \cdot 876\end{array}$ & $\begin{array}{l}\cdot 001 \\
.05 \\
.05\end{array}$ & $\begin{array}{l}\text { Schizophrenia } \\
\text { Neurosis } \\
\text { Schizophrenia }\end{array}$ & $\begin{array}{r}14 \cdot 837 \\
2 \cdot 808 \\
3 \cdot 443\end{array}$ \\
\hline $\begin{array}{l}\text { EARS: } \\
\text { No discrete lobule }\end{array}$ & & . & 107 & $15 \cdot 9$ & 56 & $41 \cdot 1$ & 46 & $47 \cdot 8$ & $22 \cdot 048$ & $\cdot 001$ & Schizophrenia & $7 \cdot 733$ \\
\hline $\begin{array}{l}\text { SKIN: } \\
\text { Soft, babyish }\end{array}$ & $\cdots$ & $\cdots$ & 107 & $36 \cdot 4$ & 56 & $55 \cdot 4$ & 46 & $41 \cdot 3$ & $5 \cdot 695$ & $\cdot 1$ & 一 & - \\
\hline
\end{tabular}

All assessments made by same observer on rating-scale basis. 209 subjects (107 controls and 102 patients) rated for all features except one. All subjects male. No feature included in differential significance columns in which contributory expected $\chi^{2}$ frequency was less than 10 and "expected" fraction of total numbers less than $0 \cdot 24$ (Lewis and Burke, 1949). 
TABLE II

LENGTH OF UPPER LIP

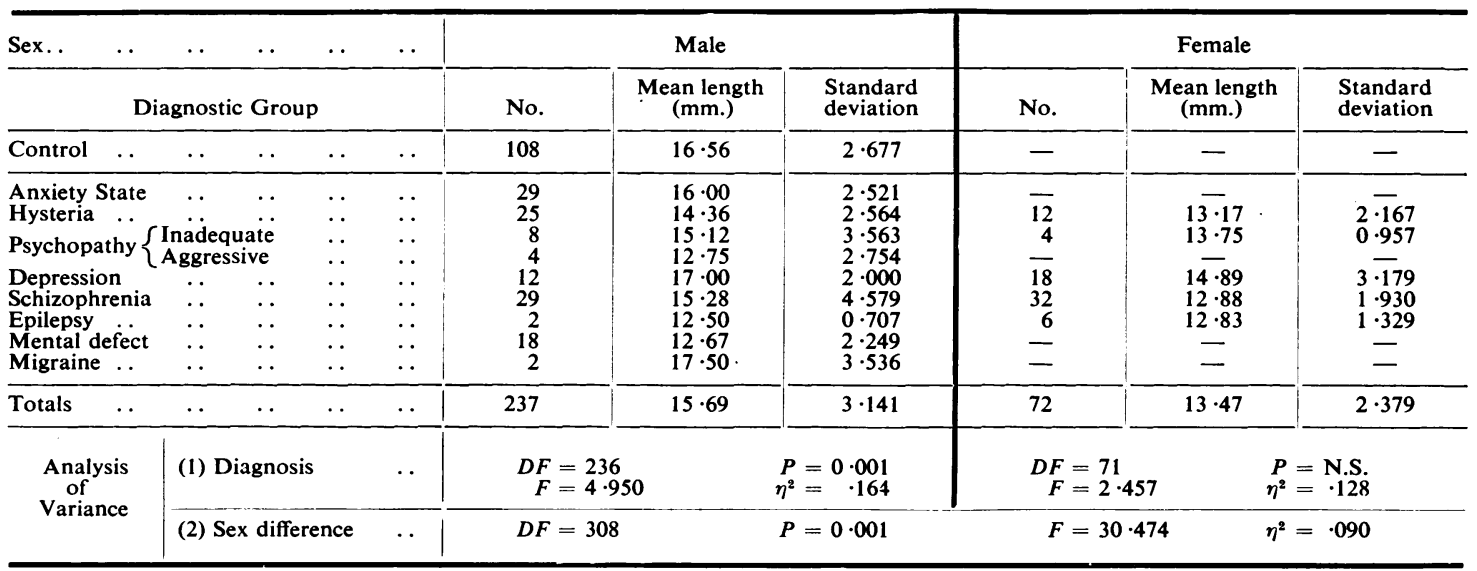

the tendencies they reveal. For all other ratings, $\chi^{2}$ is significant at least to within the 5 per cent. level of confidence.

Table II confirms the qualitative ratings of Table I with respect to the length of the upper lip. There is a large sex difference here, but apart from this, the analysis of variance, at least in the male group (there being no female representatives among the controls), indicates significantly short upper lips in patients with most types of psychiatric disturbance (except depression) and confirms Kretschmer's description of this component of his "hypoplastic" constitutional type. The high $F$ ratios representing the sex differences for mensuration of the inter-pupillary distance (Table III) might be assumed from a clinical impression of the differential facial modelling of men and women. The relationship of the distance between the midpoints of the pupils and the breadth of the face (I.P.I. or "interpupillary index") might be expected to negate this. Table IV (overleaf) shows such to be the case, and also indicates that relative wide-spacing of the eyes is significantly common to cases of anxiety state, psychopathic personality, schizophrenia, and female agitated depression, while relatively narrow-spaced eyes are to be found among male hysterics, idiopathic epileptics, and cases of migraine.

The findings recorded in Tables III and IV are echoed in Table V (overleaf). If a significant correlation exists developmentally between the mid-pupillary space and the formation of the nasal bridge, then it might be expected that the results of measurement

TABLE III

INTERPUPILLARY DISTANCE

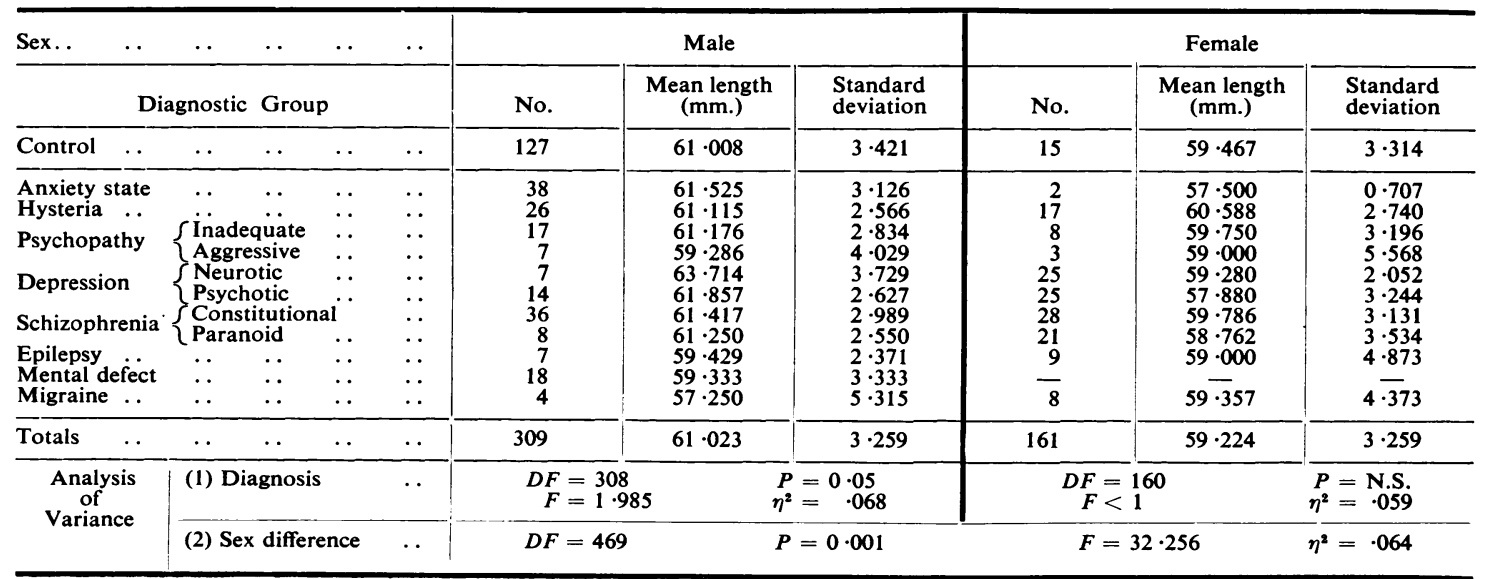


TABLE IV

DISTRIBUTION OF THE MEANS OF THE INTERPUPILLARY INDEX

\begin{tabular}{|c|c|c|c|c|c|c|c|c|c|c|}
\hline Sex.. & . & . & . & . & \multicolumn{3}{|c|}{ Male } & \multicolumn{3}{|c|}{ Female } \\
\hline \multicolumn{5}{|c|}{ Diagnostic Group } & No. & Mean Index & $\begin{array}{l}\text { Standard } \\
\text { deviation }\end{array}$ & No. & Mean Index & $\begin{array}{l}\text { Standard } \\
\text { deviation }\end{array}$ \\
\hline Control $\ldots$ & . & . & . & $\ldots$ & 128 & $46 \cdot 641$ & $3 \cdot 448$ & 15 & $44 \cdot 133$ & $2 \cdot 587$ \\
\hline $\begin{array}{l}\text { Anxiety state } \\
\text { Hysteria . . } \\
\text { Psychopathy } \\
\text { Depression } \\
\text { Schizophrenia } \\
\text { Epilepsy . } \\
\text { Mental defect } \\
\text { Migraine . . }\end{array}$ & $\begin{array}{l}\cdots \\
\left\{\begin{array}{l}\text { Ina } \\
\mathrm{Ag}\end{array}\right. \\
\mathrm{Ne} \\
\mathrm{Psy} \\
\mathrm{Co} \\
\mathrm{Pa} \\
\cdots \\
\cdots\end{array}$ & $\begin{array}{l}\text {. } \\
\text { quate } \\
\text { essive } \\
\text { otic } \\
\text { ootic } \\
\text { titutional } \\
\text { loid } \\
\ldots \\
\ldots \\
\text {. }\end{array}$ & $\begin{array}{l}\cdots \\
\cdots \\
\cdots \\
\cdots \\
\cdots \\
\ldots \\
\cdots \\
\cdots\end{array}$ & $\begin{array}{l}\ldots \\
\ldots \\
\ldots \\
\ldots \\
\ldots \\
\ldots \\
\ldots \\
\ldots\end{array}$ & $\begin{array}{r}37 \\
26 \\
19 \\
8 \\
9 \\
17 \\
34 \\
10 \\
6 \\
17 \\
3\end{array}$ & $\begin{array}{l}42 \cdot 270 \\
45 \cdot 962 \\
46 \cdot 368 \\
47 \cdot 125 \\
46 \cdot 444 \\
46 \cdot 235 \\
48 \cdot 529 \\
46 \cdot 700 \\
43 \cdot 500 \\
45 \cdot 765 \\
44 \cdot 000\end{array}$ & $\begin{array}{l}3 \cdot 746 \\
2 \cdot 645 \\
2 \cdot 793 \\
1 \cdot 727 \\
3 \cdot 046 \\
2 \cdot 840 \\
3 \cdot 578 \\
5 \cdot 229 \\
2 \cdot 739 \\
2 \cdot 223 \\
4 \cdot 359\end{array}$ & $\begin{array}{r}2 \\
19 \\
5 \\
3 \\
16 \\
29 \\
41 \\
10 \\
11 \\
6\end{array}$ & $\begin{array}{l}46 \cdot 500 \\
45 \cdot 947 \\
51 \cdot 600 \\
46 \cdot 000 \\
47 \cdot 000 \\
45 \cdot 724 \\
47 \cdot 244 \\
47 \cdot 200 \\
46 \cdot 000 \\
45 \cdot 333\end{array}$ & $\begin{array}{l}0 \cdot 707 \\
2 \cdot 718 \\
5 \cdot 030 \\
3 \cdot 605 \\
3 \cdot 812 \\
3 \cdot 172 \\
3 \cdot 793 \\
3 \cdot 765 \\
4 \cdot 858 \\
3 \cdot \overline{6} \\
3 \cdot 615\end{array}$ \\
\hline Totals & $\cdots$ & $\cdots$ & $\cdots$ & $\cdots$ & 314 & $46 \cdot 701$ & $3 \cdot 403$ & 157 & $46 \cdot 427$ & $3 \cdot 702$ \\
\hline \multirow{2}{*}{$\begin{array}{c}\text { Analysis } \\
\text { of } \\
\text { Variance }\end{array}$} & \multicolumn{3}{|c|}{ (1) Diagnosis } & . & \multicolumn{2}{|c|}{$\begin{aligned} D F & =313 \\
F & =2 \cdot 003\end{aligned}$} & $\begin{array}{l}=0.05 \\
=\quad .068\end{array}$ & \multicolumn{2}{|c|}{$\begin{aligned} D F & =156 \\
F & =2 \cdot 197\end{aligned}$} & $\begin{array}{c}P=0.05 \\
\eta^{2}=\cdot 131\end{array}$ \\
\hline & \multicolumn{3}{|c|}{ (2) Sex difference } & $\ldots$ & \multicolumn{2}{|c|}{$D F=470$} & N.S. & \multicolumn{2}{|c|}{$F<1$} & $=.00136$ \\
\hline
\end{tabular}

of the depth of the nasal root should bear a relationship to the variables controlling these ocular proportions.

Table $\mathrm{V}$ shows that measurements of the nasal root depth are significantly decreased for psychotics but not for massed neurotics, the increased width found in patients with anxiety states apparently cancelling out the narrow interpupillary distance characterizing hysterical patients.

\section{TABLE V}

INFLUENCE OF DIAGNOSIS ON DISTRIBUTION OF MEANS OF DEPTH OF NASAL ROOT Measured in $\mathrm{mm}$. on 244 male subjects

\begin{tabular}{|c|c|c|c|c|c|}
\hline \multicolumn{2}{|c|}{ Diagnostic Group } & \multirow{2}{*}{$\begin{array}{l}\text { No. } \\
106\end{array}$} & \multirow{2}{*}{$\begin{array}{l}\begin{array}{l}\text { Mean } \\
\text { depth } \\
(\mathrm{mm} .)\end{array} \\
16 \cdot 953\end{array}$} & \multirow{2}{*}{$\begin{array}{c}\begin{array}{c}\text { Standard } \\
\text { Deviation }\end{array} \\
2 \cdot 723\end{array}$} & \multirow{2}{*}{$\begin{array}{c}\begin{array}{c}\text { Analysis } \\
\text { of } \\
\text { Variance }\end{array} \\
D F=243\end{array}$} \\
\hline Control $\quad \ldots$ & $\ldots$ & & & & \\
\hline Neurosis .. & . & 59 & $17 \cdot 610$ & $2 \cdot 666$ & $0 \cdot 001$ \\
\hline Depression & . & 22 & $15 \cdot 273$ & $2 \cdot 979$ & $F=12 \cdot 877$ \\
\hline Schizophrenia & . & 57 & $14 \cdot 895$ & $2 \cdot 418$ & $\eta^{2}=$ \\
\hline Total & $\ldots$ & 244 & $16 \cdot 480$ & $2 \cdot 854$ & \\
\hline
\end{tabular}

Table VI completes these quantitative assessments and reveals the tendency towards fixation at morphologically immature levels in cases of psychiatric disorders.

Table VII represents a crude attempt at constructing an "Index of Morphological Maturity". The twenty traits and measurements which best differentiated between controls and psychiatric abnormals were selected, and the incidence of each trait for the individuals of the various diagnostic sub-groups studied was totalled. There was no significant sex difference in these totals, although the differential sex patterning showed a skewing in the expected direction. From Table VII it can be seen that, as the severity of the psychiatric diagnosis increases, so does the weight of the loading of features of morphological ontogenetic dysplasia, the greatest incidence of such features being present in "constitutional" (hebephrenic, catatonic, and simplex) schizophrenia, and in (female) epilepsy.

Table VIII has already been briefly referred to (p. 171). If these features which have been examined really do represent dysplasias of the processes of maturation, then it is logical to assume that, whatever the relative velocity of individual growth and development within the structure of physiological time (Du Nouy, 1936), the progress of ontogenesis should always be towards a diminution of such dysplasias. Table VIII demonstrates the significant march of that progress within the limited age ranges studies. It also shows that, with standard deviations approximately equivalent between the groups and for the 10-year periods between fifteen and 44 years, a slower drive towards maturity is inherent in the psychiatrically abnormal patients than exists in the individuals of the healthy group; the reduction in the loading of morphological dysplastic features was 1.8 in the controls and only $1 \cdot 2$ in the patients $(P=\cdot 05$ in each case).

\section{Discussion}

The personality of Man is a mosaic, the resultant of the integration of a vast number of variables, fitting, jigsaw-fashion, into the matrix of the whole. It is no static thing, but dynamic, changing and structured in biological time. Everyone is familiar with the fact that behaviour patterns are 
TABLE VI

DIFFERENTIAL INCIDENCE OF HYPEREXTENSIBLE LIGAMENTS (“DOUBLE JOINTEDNESS") AT THUMB METACARPO-PHALANGEAL ARTICULATION

\begin{tabular}{|c|c|c|c|c|c|c|c|c|c|c|}
\hline \multicolumn{5}{|c|}{ Diagnostic Group } & \multirow{2}{*}{$\begin{array}{c}\text { No. } \\
46\end{array}$} & \multirow{2}{*}{$\begin{array}{c}\text { Incidence } \\
7\end{array}$} & \multirow{2}{*}{$\begin{array}{c}\begin{array}{c}\text { Percentage } \\
\text { Incidence }\end{array} \\
15 \cdot 2\end{array}$} & \multirow{2}{*}{$\begin{array}{c}\begin{array}{c}\text { Contribution } \\
\text { to } \chi^{2}\end{array} \\
8 \cdot 165\end{array}$} & \multirow{2}{*}{$\begin{array}{c}\begin{array}{c}\text { Negative or } \\
\text { positive } \\
\text { contribution }\end{array} \\
--\end{array}$} & \multirow{3}{*}{$\begin{array}{c}\begin{array}{c}\text { Statistical } \\
\text { significance }\end{array} \\
D F=3 \\
P=.01\end{array}$} \\
\hline Control .. & $\cdots$ & $\cdots$ & $\cdots$ & $\cdots$ & & & & & & \\
\hline Neurosis . & . & . & .. & . & 38 & 16 & $42 \cdot 1$ & $0 \cdot 757$ & + & \\
\hline \multirow{2}{*}{$\begin{array}{l}\text { Depression } \\
\text { Schizophrenia }\end{array}$} & $\cdots$ & $\cdots$ & $\cdots$ & $\cdots$ & 56 & 20 & $35 \cdot 7$ & 0.031 & + & \multirow{3}{*}{$\begin{array}{l}\text { Principal } \\
\text { contributor to } \\
\text { total } \chi^{2} \text { is } \\
\text { Schizophrenia }\end{array}$} \\
\hline & .. & .. & . & $\cdots$ & 41 & 21 & $51 \cdot 2$ & $4 \cdot 513$ & + & \\
\hline Total & $\ldots$ & .. & $\ldots$ & $\ldots$ & 181 & \multicolumn{4}{|c|}{ Total $\chi^{2}=13 \cdot 466$} & \\
\hline
\end{tabular}

TABLE VII

MORPHOLOGY OF MATURITY INDEX

Mean incidence by diagnostic group and sex of twenty possible features of morphological ontogenetic dysplasia.

\begin{tabular}{|c|c|c|c|c|c|c|c|c|c|c|c|}
\hline Sex.. & . & . & . & $\cdots$ & $\cdots$ & & Male & & & Female & \\
\hline \multicolumn{6}{|c|}{ Diagnostic Group } & No. & $\begin{array}{c}\text { Mean } \\
\text { incidence } \\
N / 20\end{array}$ & $\begin{array}{l}\text { Standard } \\
\text { deviation }\end{array}$ & No. & $\begin{array}{c}\text { Mean } \\
\text { incidence } \\
N / 20\end{array}$ & $\begin{array}{l}\text { Standard } \\
\text { deviation }\end{array}$ \\
\hline Control & $\ldots$ & $\cdots$ & $\ldots$ & . & $\ldots$ & 124 & $5 \cdot 532$ & $2 \cdot 661$ & 13 & $4 \cdot 846$ & $2 \cdot 882$ \\
\hline \multicolumn{2}{|c|}{$\begin{array}{l}\text { Anxiety state } \\
\text { Hysteria .. } \\
\text { Psycopathy } \\
\text { Depression } \\
\text { Schizophrenia }\end{array}$} & $\left\{\begin{array}{l}\ldots \\
\text { Ina } \\
\mathrm{Ag} \\
\mathrm{Ne} \\
\mathrm{Psy} \\
\mathrm{Co} \\
\mathrm{Par} \\
\ldots \\
\ldots\end{array}\right.$ & $\begin{array}{c}\ldots \\
\text { qua } \\
\text { ssiv } \\
\text { tic } \\
\text { otic } \\
\text { ituti } \\
\text { oid } \\
\ldots \\
\ldots\end{array}$ & $\begin{array}{l}\ldots \\
\cdots \\
\ldots \\
\cdots \\
\cdots \\
\cdots \\
\cdots \\
\cdots\end{array}$ & $\begin{array}{l}\ldots \\
\ldots \\
\ldots \\
\ldots \\
\ldots \\
\ldots \\
\cdots \\
\ldots\end{array}$ & $\begin{array}{r}40 \\
27 \\
20 \\
7 \\
10 \\
13 \\
9 \\
9 \\
5 \\
4\end{array}$ & $\begin{array}{l}8 \cdot 050 \\
8 \cdot 519 \\
8 \cdot 500 \\
7 \cdot 000 \\
7 \cdot 500 \\
7 \cdot 615 \\
9 \cdot 778 \\
7 \cdot 444 \\
7 \cdot 000 \\
8 \cdot 000\end{array}$ & $\begin{array}{l}2 \cdot 470 \\
1 \cdot 762 \\
2 \cdot 565 \\
2 \cdot 081 \\
2 \cdot 677 \\
2 \cdot 534 \\
3 \cdot 032 \\
2 \cdot 789 \\
0 \cdot 707 \\
0 \cdot 816\end{array}$ & $\begin{array}{r}4 \\
14 \\
3 \\
2 \\
16 \\
17 \\
12 \\
4 \\
10 \\
8\end{array}$ & $\begin{array}{r}6 \cdot 250 \\
8 \cdot 357 \\
9 \cdot 000 \\
4 \cdot 500 \\
6 \cdot 125 \\
7 \cdot 176 \\
10 \cdot 000 \\
8 \cdot 250 \\
10 \cdot 700 \\
6 \cdot 500\end{array}$ & $\begin{array}{l}0 \cdot 500 \\
3 \cdot 249 \\
0 \\
3 \cdot 536 \\
3 \cdot 008 \\
2 \cdot 766 \\
2 \cdot 796 \\
2 \cdot 630 \\
2 \cdot 312 \\
2 \cdot 000\end{array}$ \\
\hline Totals & $\cdots$ & $\cdots$ & . & $\cdots$ & $\cdots$ & 268 & $6 \cdot 914$ & $2 \cdot 818$ & 103 & $7 \cdot 505$ & $3 \cdot 199$ \\
\hline \multirow{2}{*}{\multicolumn{2}{|c|}{$\begin{array}{l}\text { Analysis } \\
\text { of } \\
\text { Variance }\end{array}$}} & \multirow{2}{*}{\multicolumn{3}{|c|}{ (1) Diagnosis }} & . & \multicolumn{2}{|c|}{$\begin{aligned} D F & =267 \\
F & =7.909\end{aligned}$} & $\begin{array}{c}P=0 \cdot 001 \\
\eta^{2}=\quad \cdot 235\end{array}$ & \multicolumn{2}{|c|}{$\begin{aligned} D F & =102 \\
F & =4.692\end{aligned}$} & $\begin{aligned} P & =0.001 \\
\eta^{2}= & .338\end{aligned}$ \\
\hline & & & & & $\cdots$ & \multicolumn{2}{|c|}{$D F=370$} & $3 \cdot 027$ & \multicolumn{2}{|c|}{$\boldsymbol{P}=$ N.S. } & $\eta^{2}=.008$ \\
\hline
\end{tabular}

TABLE VIII

PROGRESSIVE DIMINUTION AS AGE ADVANCES OF LOADING OF FEATURES OF MORPHOLOGICAL IMMATURITY IN BOTH CONTROL AND PSYCHIATRICALLY ABNORMAL GROUPS

Not until the sixth decade does the psychiatrically abnormal patient grow up to the morphological maturity reached by the control group in the second decade

\begin{tabular}{|c|c|c|c|c|c|c|c|c|c|c|c|}
\hline \multicolumn{6}{|c|}{ Diagnostic Group } & \multicolumn{3}{|c|}{ Controls } & \multicolumn{3}{|c|}{ Psychiatric Abnormals } \\
\hline \multicolumn{6}{|c|}{$\begin{array}{l}\text { Age range } \\
\text { (years) }\end{array}$} & No. & $\begin{array}{c}\text { Mean } \\
\text { incidence } \\
N / 20\end{array}$ & $\begin{array}{l}\text { Standard } \\
\text { deviation }\end{array}$ & No. & $\begin{array}{c}\text { Mean } \\
\text { incidence } \\
N / 20\end{array}$ & $\begin{array}{l}\text { Standard } \\
\text { deviation }\end{array}$ \\
\hline \multicolumn{6}{|c|}{$\begin{array}{l}15-24 \\
25-34 \\
35-44 \\
45-54 \\
55-64\end{array}$} & $\begin{array}{r}69 \\
50 \\
17 \\
0 \\
0\end{array}$ & $\begin{array}{c}5 \cdot 971 \\
5 \cdot 220 \\
4 \cdot 176 \\
- \\
-\end{array}$ & $\begin{array}{c}2 \cdot 657 \\
2 \cdot 683 \\
2 \cdot 430 \\
- \\
-\end{array}$ & $\begin{array}{r}83 \\
66 \\
30 \\
10 \\
6\end{array}$ & $\begin{array}{l}8 \cdot 228 \\
8 \cdot 439 \\
7 \cdot 033 \\
7 \cdot 100 \\
6 \cdot 000\end{array}$ & $\begin{array}{l}2 \cdot 534 \\
2 \cdot 684 \\
2 \cdot 632 \\
2 \cdot 767 \\
1 \cdot 673\end{array}$ \\
\hline Totals & $\cdots$ & $\cdots$ & $\cdots$ & . & . & 136 & $5 \cdot 471$ & $2 \cdot 689$ & 195 & $7 \cdot 990$ & $2 \cdot 644$ \\
\hline \multicolumn{6}{|c|}{ Analysis of Variance } & \multicolumn{2}{|c|}{$\begin{aligned} D F & =135 \\
F & =3 \cdot 507\end{aligned}$} & $\begin{array}{c}P=0.05 \\
\eta^{2}=\quad .050\end{array}$ & \multicolumn{2}{|c|}{$\begin{aligned} D F & =194 \\
F & =2 \cdot 868\end{aligned}$} & $\begin{array}{c}P=0.05 \\
\eta^{2}=\quad .057\end{array}$ \\
\hline
\end{tabular}

tolerated in infancy and early childhood which would place adults either in prison or in a mental hospital. But, just as these patterns are normally outgrown. by integration with modes of behaviour progressively more in accord with the cultural standards accepted locally as typical of those of adult reaction, so the physical bodily characteristics of infancy and childhood change with growth and development from those characterizing immaturity to those typifying the relative maturation of adulthood. And, 
pari passu, these changes occur in parallel-emotional development proceeding in step with changes of physique, constitution, and bodily configuration. If these processes occurred with the same speed and to the same degree, both among individuals and among the innumerable components making up the Gestalt of each personality, then one might observe among the members of any culture or people a sameness or identity much greater than is perceptible in fact. Growth and development do indeed lead to much similarity among individuals, e.g. height and weight are reached to within a certain limited range, and from these measurements the calculation of a "ponderal index" provides a useful classification of groups. But the distribution of individuals for these measurements falls along a Gaussian curve and is only crudely related to factors of differential growth. The morphological features examined in this paper, although similar in many respects to other indices, differ from them in representing a variety of potentials to development which may or may not be realized in the attainment of adulthood. All babies, for example, are born with hyperextensible ligaments, but a cross-section of the healthy British population shows that only $15 \cdot 2$ per cent. of adults show such hyperextensibility, while the remaining 84.8 per cent. have lost it. We may therefore assume that "double-jointedness" changes with advancing chronological age, and that its retention in adulthood represents an unrealized potential to differential development. But this is not to say that these healthy adults are morphologically "immature" in any general sense of that term; they are only immature with respect to this one characteristic. We have seen that a number of such morphological dysplastic features are found normally distributed in a population sample such as our controls; but we have also seen that, when twenty such features are sampled and their total incidence examined, their number gradually diminishes with advancing age, and also that the fewer such characters any given individual possesses at any one time, the less likely is he to possess also the psychological characters of emotional immaturity, and the less likely is he to break down with psychiatric disorder, as the stress of his environment becomes ever more severe and out of step with the progressively intricate adjustments he has to make with the advance of his chronological age.

We have also shown that, grouping the mentally ill patients together and comparing their morphological growth index with that of the controls on an age range basis, then, for these criteria at least, not until the age of 60 does the emotionally unstable and dysplastic individual mature morphologically to the extent reached by the healthy individual at the age of 20. The implications of this are not surprising when such findings are reviewed in terms of what we know clinically of the prognosis of psychiatric patients. The psychiatrist sees surprisingly few middle-aged neurotics or idiopathic epileptics in his clinic or mental hospital practice as compared with similar patients in younger age groups.

Just as the differential physical characteristics of individuals provide visual confirmation of their unique personalities (the identical twin is an excellent example of this, emotional and behavioural characteristics appearing in step with practical somatic identity), so not only do the individual differences in morphological development appear associated with the uniqueness of individual personality, but also the pattern of a group of morphological dysplasias appears associated with the tendency for an individual to break down in a particular psychiatric fashion if stress becomes intolerable. Thus, such features of morphological dysplasia as blue eyes, long curved lashes, pouting lips, and a soft skin are found predominantly among neurotics; wide-spaced eyes and a shallow nasal root among depressives; and a scanty upper lip, ears without discrete lobulation, a high interpupillary index, double-jointedness, and persistent remnants of the epicanthic fold among schizophrenics. Among psychoneurotics, the case of anxiety state with his wide-spaced eyes and high interpupillary index is capable of morphological differentiation from the hysteric with his short upper lip and relatively low I.P.I. Similarly, among schizophrenics, the paraphrenic may be distinguished from the hebephrenic, catatonic, and dementia praecox simplex by the total of dysplastic features in the index of morphological maturity being less, though still heavy by comparison with other diagnostic groups studied. It should be emphasized that these predictive conclusions do not refer to the presence of isolated morphological characteristics but only to the pattern of their distribution in a total loading of dysplastic features in excess of that found in a normal healthy population.

We all grow up unevenly and differentially to varying degrees and at varying velocities. This unevenness is reflected in our emotions, intelligence, and constitution; in our immunity to disease and somatic configuration; in the functioning of our bodily processes and the speed and pattern of our homeostatic responses to the stresses of living. It is just this unevenness which makes us unique personalities, distinct one from another as well as culturally, racially, and anthropologically. One 
of the purposes of this paper is to suggest that, at least for the morphological variables of the processes of growth, a surfeit of such dysplasia, too uneven a loading of immature characteristics, bodes ill for the integrity of psychological functioning and contributes manifestly to the causation of mental disease.

\section{SUMMARY}

(1) Anthroposcopic observations of 28 , and anthropometric measurement of seven features of morphological growth dysplasia were made on 261 healthy adult subjects, 302 psychiatric patients, twelve patients with migraine, and eighteen mental defectives.

(2) Qualitatively and quantitatively, the patients revealed a persistence of characteristics of morphological immaturity significantly greater than that in the controls.

(3) The loadings of immature and dysplastic features showed a differential sex distribution and a progressive decline with age. The totals were significantly higher for the patients than for the controls.

(4) The differential distribution of the 31 separate morphological traits formed relatively distinct patterns for each of the psychiatrically abnormal groups; this enabled gross diagnostic predictions to be made on ontogenetic grounds.
(5) The implications of the findings are discussed, especially from the point of view of personality development.

I am greatly indebted to all my colleagues who have assisted in this investigation by making available clinical material for evaluation, to those mentioned in the text of this paper as well as to those on the staff of the Maudsley Hospital. I am grateful for the facilities granted for the work by Professor Aubrey Lewis, Head of the Department of Psychiatry at this Institute, and by Captain H. A. Dilley of the War Office, and for the statistical advice and computational assistance freely given by $\mathrm{Mr}$. A. Lubin and Mr. G. K. McArthur. Lastly I gladly acknowledge the financial assistance made available to me, since part of this work was done during the tenure of a Fellowship in Medicine of the Nuffield Foundation.

\section{REFERENCES}

Bolk, L. (1924). Verh. Akad. Wet., Amst., 27, 329.

Draper, G., Dupertuis, C. W., and Caughey, J. L., Jr. (1944). "Human Constitution in Clinical Medicine". Hoeber, New York.

Du Nouy, P. Lecomte (1936). "Biological Time". Methuen, London. Kline, N. S., and Tenney, A. M. (1950). Amer. J. Psychiat., 197, 434. Kretschmer, E. (1936). "Physique and Character", trans. W. J. H. Sprott, 2nd ed. Kegan Paul, London.

Lewis, D., and Burke, C. J. (1949). Psychol. Bull., 46, 433.

Sheldon, W. H., and Stevens, S. S. (1942). "The Varieties of Temperament". Harper, New York.

" and Tucker, W. B. (1940). "The Varieties of Human Physique". Harper, New York.

Slater, E. T. O. (1951). In "Recent Progress in Psychiatry", vol. 2, chap. 1. Churchill, London.

Smyth, C., and Young, M. (1932). Spec. Rep. Ser. med. Res. Coun., No. 17i. H.M.S.O., London. 